\title{
How can we improve antidepressant adherence in the management of depression? A targeted review and 10 clinical recommendations
}

\author{
Marco Solmi, ${ }^{1,2 *}$ iD Alessandro Miola, ${ }^{1 *}$ Giovanni Croatto, ${ }^{1}$ Giorgio Pigato, ${ }^{2}$ Angela Favaro, ${ }^{1,2}$
} Michele Fornaro, ${ }^{3,4}$ iD Michael Berk, ${ }^{5,6,7}$ Lee Smith, ${ }^{8}$ Joao Quevedo,,${ }^{9,10,11,12}$ (iD Michael Maes, ${ }^{13}$ ID Christoph U. Correll, ${ }^{14,15,16}$ André F. Carvalho ${ }^{13,17,18}$ iD

${ }^{1}$ Dipartimento di Neuroscienze, Università di Padova, Padova, Italy. ${ }^{2}$ Azienda Ospedale Università di Padova, Padova, Italy. ${ }^{3}$ Dipartimento di psichiatria, Università Federico II, Napoli, Italy. ${ }^{4}$ Polyedra, Teramo, Italy. ${ }^{5}$ Institute for Mental and Physical Health and Clinical Translation (IMPACT Strategic Research Centre), School of Medicine, Barwon Health, Deakin University, Geelong, Victoria, Australia. ${ }^{6}$ Department of Psychiatry, Orygen - The Centre of Excellence in Youth Mental Health, Melbourne, Victoria, Australia. ${ }^{7}$ Florey Institute of Neuroscience and Mental Health, University of Melbourne, Victoria, Australia. ${ }^{8}$ Cambridge Centre for Sport and Exercise Sciences, Anglia Ruskin University, Cambridge, UK. ${ }^{9}$ Programa de Pós-Graduação em Ciências da Saúde, Laboratório de Neurociências, Unidade de Ciências da Saúde, Universidade do Extremo Sul Catarinense (UNESC), Criciúma, SC, Brazil. ${ }^{10}$ Translational Psychiatry Program, Department of Psychiatry and Behavioral Sciences, McGovern Medical School, The University of Texas Health Science Center at Houston (UTHealth), Houston, TX, USA.

${ }^{11}$ Department of Psychiatry and Behavioral Sciences, Center of Excellence on Mood Disorders, McGovern Medical School, UTHealth, Houston, TX, USA. ${ }^{12}$ Neuroscience Graduate Program, The University of Texas Graduate School of Biomedical Sciences at Houston, Houston, TX, USA. ${ }^{13}$ IMPACT Strategic Research Centre, Barwon Health, School of Medicine, Deakin University, Geelong, Victoria, Australia. ${ }^{14}$ Department of Psychiatry and Molecular Medicine, Donald and Barbara Zucker School of Medicine at Hofstra/Northwell, Hempstead, NY, USA. ${ }^{15}$ Department of Psychiatry, Zucker Hillside Hospital, Glen Oaks, NY, USA. ${ }^{16}$ Department of Child and Adolescent Psychiatry, Charité Universitätsmedizin, Berlin, Germany. ${ }^{17}$ Department of Psychiatry, University of Toronto, Toronto, ON, Canada. ${ }^{18}$ Centre for Addiction and Mental Health, Toronto, ON, Canada. * These authors have contributed equally to this manuscript.

\begin{abstract}
Adherence to antidepressants is crucial for optimal treatment outcomes when treating depressive disorders. However, poor adherence is common among patients prescribed antidepressants. This targeted review summarizes the main factors associated with poor adherence, interventions that promote antidepressant adherence, pharmacological aspects related to antidepressant adherence, and formulates 10 clinical recommendations to optimize antidepressant adherence. Patient-related factors associated with antidepressant non-adherence include younger age, psychiatric and medical comorbidities, cognitive impairment, and substance use disorders. Prescriber behavior-related factors include neglecting medical and family histories, selecting poorly tolerated antidepressants, or complex antidepressant regimens. Multi-disciplinary interventions targeting both patient and prescriber, aimed at improving antidepressant adherence, include psychoeducation and providing the patient with clear behavioral interventions to prevent/minimize poor adherence. Regarding antidepressant choice, agents with individually tailored tolerability profile should be chosen. Ten clinical recommendations include four points focusing on the patient (therapeutic alliance, adequate history taking, measurement of depressive symptoms, and adverse effects improved access to clinical care), three focusing on prescribing practice (psychoeducation, individually tailored antidepressant choice, simplified regimen), two focusing on mental health services (improved access to mental health care, incentivized adherence promotion and monitoring), and one relating to adherence measurement (adherence measurement with scales and/or therapeutic drug monitoring).
\end{abstract}

Keywords: Adherence; compliance; antidepressant; therapeutic drug monitoring; psychiatry; depression; mood disorders; treatment

\section{Introduction}

Depression is a prevalent and disabling mental disorder projected to become the leading source of disease burden globally by $2030 .^{1}$ Depressive episodes often evolve into

Correspondence: André F. Carvalho, Centre for Addiction and Mental Health, Bell Gateway Building, 100 Stokes Street, 4th Floor, Toronto, ON, M6J 1H4, Canada.

E-mail: andre.carvalho@camh.ca

Submitted Mar 01 2020, accepted Apr 02 2020, Epub Jun 012020. chronic or recurring depressive disorders, with detrimental consequences over the entire life span. ${ }^{2,3}$

In general, psychotropic medications work as effectively as medications in other fields of medicine. ${ }^{4}$ All antidepressants are more efficacious than placebo for
How to cite this article: Solmi M, Miola A, Croatto G, Pigato G, Favaro A, Fornaro M, et al. How can we improve antidepressant adherence in the management of depression? A targeted review and 10 clinical recommendations. Braz J Psychiatry. 2021;43:189-202. http://dx.doi.org/10.1590/1516-4446-2020-0935 
adults with major depressive disorder, with clinical response to treatment usually defined as a reduction of $\geqslant 50 \%$ in the total score on a standardized observerrated scale for depression. ${ }^{5}$ This large body of evidence is consistent with recommendations from an international Task Force of the World Federation of Societies of Biological Psychiatry (WFSBP), which indicates that many different antidepressants are available for effective acute, continuation, and maintenance treatment of unipolar depressive disorders in adults. ${ }^{6}$ It should be noted, however, that "newer" antidepressants, such as selective serotonin reuptake inhibitors (SSRIs), and vortioxetine, have variable efficacy/tolerability profiles in adults compared to the older tricyclic antidepressants (TCA).$^{6-8}$

Regarding safety, a recent large synthesis of the evidence including around 1,000 individual observational studies concluded that overall antidepressants are safe in adults. Most of the purported serious adverse events; that have been attributed to antidepressants, including abortion, autism in offspring, and malformations during pregnancy, as well as a higher risk of suicide attempts in adolescents, are not supported by convincing evidence, and are probably driven by confounding by indication. ${ }^{9,10}$

A different construct from safety is acceptability, which is frequently measured as dropout rates due to any reason in randomized controlled trials (RCTs) or cohort studies. ${ }^{5}$ It has been stated that "is not that there are not effective medications... but patients so often refuse to take them... because of a lack of information, poor medical advice, stigma, or fear of personal or professional reprisals, they do not seek treatment at all."11 Dropout rates are a complex indirect proxy measure of inefficacy and intolerability as well as adherence, which is defined in a broader sense as "the extent to which a person's behavior coincides with the medical advice given." ${ }^{12}$ Medication adherence rates in depression are relatively low: approximately $30 \%$ of patients with depression prematurely withdraw treatment entirely, despite prolonged medical prescriptions. ${ }^{13}$ However, it turns out that this is not very different from non-adherence in general medical disorders, with documented rates between $20-50 \% .{ }^{14}$ Such low adherence rates are particularly concerning from a clinical perspective, since antidepressant adherence is crucial for adequate treatment outcomes, especially considering that early discontinuation of prescribed antidepressants would not allow sufficient exposure to exert a therapeutic effect ("antidepressant lag phase"). ${ }^{15}$ Early adherence is crucial to successful depression treatment, but 30 to $60 \%$ of patients discontinue antidepressants within 3 months. ${ }^{16}$ The reported consequences of antidepressant non-adherence in patients with depressive disorders include relapse and symptom recurrence, chronicity, poor psychosocial outcomes, and increased suicide rates. ${ }^{17}$ Antidepressant non-adherence also has a significant impact on health care utilization and costs, ${ }^{18}$ including increased emergency department visits and hospitalizations. ${ }^{19}$ Antidepressant non-adherence might, at least in part, explain why a significant percentage of patients do not achieve full remission of depressive symptoms in "real-world" clinical practice, ${ }^{20-22}$ and why approximately $50 \%$ of patients experience recurrence after recovery from the index episode. ${ }^{23}$
Given the high social, clinical, and economic impact of antidepressant non-adherence among patients with depressive disorders, it is clinically crucial to recognize factors associated with non-adherence to antidepressants. ${ }^{24}$ Furthermore, clinicians should be informed about which strategies have an adequate level of evidence to enhance antidepressant adherence.

Thus, the objectives of the current focused review were to summarize factors influencing antidepressant adherence and to discuss strategies to promote adherence to antidepressants. Lastly, we aimed to provide practical clinical recommendations to maximize adherence to antidepressants.

\section{Methods}

A comprehensive literature search was performed in PubMed, Cochrane Database of Systematic Reviews, and Scopus, combining the following keywords: ("adherence" OR "compliance") AND ("antidepressant"” OR "vortioxetine" OR "SSRl" OR "SNRI" OR "NaSSA" OR "TCA" OR "NRI"), supplemented by names of antidepressants molecules (i.e., sertraline, amitriptyline, trazodone, mirtazapine, duloxetine, etc.). The full list of search keys is available upon request.

Information was summarized according to a predefined theoretical and clinical framework, as follows. First, factors influencing adherence were categorized into prescriber-related or service-related factors and patientrelated or environment-related factors. Second, we provided an overview of the most specific (i.e., targeting adherence) interventions promoting antidepressant adherence. Third, the pharmacodynamic properties of medications were discussed relative to their impact on the tolerability of antidepressants. Fourth, we provided clinicians with 10 simple rules to maximize antidepressant adherence.

\section{Results}

\section{Factors influencing antidepressant adherence}

Several factors are proposed as putative risk or protective factors for poor adherence to antidepressants. Such factors can be classified into patient/environment or prescriber/service-related. ${ }^{25,26}$ The most relevant antidepressant adherence-modulating factors emerging from the present focused review are listed in Box 1.

Among patient-related factors, depression itself and the severity of depressive symptoms can lead to a poor motivation to engage and persist, in particular when poor insight, hopelessness, amotivation, and delusional thought content drive the patient's beliefs and behavior. A metaanalysis has shown that medication non-adherence is three-fold higher in patients with depression compared to other conditions, such as anxiety or other medical disorders. ${ }^{27}$ Moreover, younger age ( $<40$ years old), comorbid substance use and personality disorders, patients' beliefs, poor insight, and illness severity are also factors that should be routinely assessed since they can predict an increased risk of poor adherence. ${ }^{24}$ According to a meta-analysis, cognitive impairment is also associated 
Box 1 Factors negatively influencing adherence to antidepressants

\begin{tabular}{|ll|}
\hline Prescriber/service-related factors & Patient/environment-related factors \\
Poor instructions & Higher depression severity - Illness severity \\
Lack of psychoeducation about the mental health condition and & Poor insight of illness \\
its treatment & Cognitive impairment \\
Polypharmacotherapy & Psychiatric comorbidity - Personality disorders - Substance abuse \\
Complex dosing regimen & Medical comorbidities - Pregnancy \\
Lack of support from or availability of health providers & Younger age ( $\leq 25$ years) \\
Low frequency of psychiatric follow-up & Loneliness in elderly \\
Poor therapeutic alliance & Higher psychological reactivity \\
Choosing medications with a history of side effects & Stigma - Peer pressure-culture \\
Choosing medications with a history of lack of efficacy & Ethnic minority \\
Choosing medications with clinically relevant unfavorable & Low socioeconomic status \\
interactions or formulation & Negative medication beliefs \\
One-size-fits-all and non-personalized approach & \\
Poor access to care - Fragmented care & \\
\hline
\end{tabular}

with depression. ${ }^{28}$ Deficits in attention and working memory, among others, can be an additional barrier to medication adherence in subjects with depression. ${ }^{28,29}$ Apart from clinical features pertinent to depression itself, several other patient-related factors play a role in poor adherence. For instance, given the frequent comorbidity between depression and personality disorders, ${ }^{30,31}$ which can affect almost half of the patients with depression, ${ }^{30}$ impulsivity, interpersonal issues, and dysregulated emotional responses can translate into poor medication adherence, in terms of either no medication intake or medication abuse.

Comorbidity of depression with substance and behavioral addictions is frequent as well. For example, national survey data show an almost four-fold increase of depression in subjects with substance abuse (odds ratio [OR] $3.80,95 \%$ confidence interval $[95 \% \mathrm{Cl}] 3.02-4.78),{ }^{32}$ and other epidemiological evidence suggests that as many as $25 \%$ of subjects with pathological gambling are also affected by depression. ${ }^{33}$ Given the evidence supporting the association between psychiatric comorbidities and poor medication adherence, subjects with comorbid personality or substance-related disorders are at a particularly high risk of poor antidepressant adherence. ${ }^{34}$ Beyond psychiatric illness, medical comorbidities can also be associated with poor psychotropic and non-psychotropic medication adherence. For instance, poor antidepressant adherence has been associated with poor $\mathrm{HbA} 1 \mathrm{c}$ control in subjects with diabetes. ${ }^{35}$ Conversely, it could be expected that subjects with poor metabolic control and poor adherence to medical treatments are also at increased risk of poor antidepressant adherence.

Beyond comorbidities, given that pregnancy is a general relative contraindication to a large group of medications, and given the poor information on risk of untreated illness vs. medications adverse events and disease induced teratogenicity, most pregnant women refuse to take medications during pregnancy. ${ }^{36,37}$ Hence, poor adherence to antidepressants should be expected in pregnant women. Age also has strong "inverted U" shaped associations with adherence, being lowest in extreme age ranges, and higher in adults. For example, adults, but not elderly, seem to have better medication compliance than adolescents, possibly due to less impulsivity, and more awareness of the underlying disease. ${ }^{16}$ Illness acceptance is an evolving process and it often takes a few episodes before an individual fully accepts the presence of illness, and owns the necessity for proactive engagement to manage the illness. An initial beneficial or adverse experience with treatment powerfully molds future treatment expectation and adherence. Older age, yet in adults, not in the elderly, positive attitudes to antidepressants, and previous experiences or vicarious experiences of depression or antidepressant treatment predict better adherence or persistence. $^{38}$ Conversely, the elderly, who might experience loneliness and social withdrawal, have multiple medical comorbidities, complex medication regimens, and cognitive impairment, which are all associated with poor medication adherence in general, could be at risk for poor adherence to antidepressants as well. ${ }^{39,40}$ Greater assistance and surveillance by caregivers could also somewhat mitigate that greater risk of medication non-adherence. Furthermore, psychological reactivity can play a role in adherence to prescribed medications. Psychological reactivity is defined as unpleasant motivational arousal that emerges when people experience a threat to or loss of their free behaviors. It serves as a motivator to restore one's freedom. The amount of reactivity depends on the importance of the threatened freedom and the perceived magnitude of the threat. ${ }^{41}$ Higher psychological reactivity seems to predict poorer compliance to medical prescriptions. ${ }^{42}$ High levels of self-stigma are also associated with increased risk for discontinuation of medications without a psychiatrist's recommendation. ${ }^{43}$ Moreover, being part of an ethnic or racial minority group increases the risk of early poor adherence to antidepressants, ${ }^{16}$ with elderly subjects facing similar barriers to antidepressant medication adherence across different ethnic minorities. ${ }^{44}$ Also, low socioeconomic status predicts early non-adherence to antidepressants. ${ }^{45}$ Finally, the environment in which a person lives and peer pressure can also contribute to improvement or be detrimental for antidepressant adherence. ${ }^{46,47}$

A comparable range of prescriber and health servicerelated factors can influence adherence to antidepressants. First, poor psychoeducation regarding biological and psychological mechanisms underlying depression ${ }^{48,49}$ and regarding the rationale underlying the indication to treat depressive disorder with medications can negatively affect adherence. Similarly, poor instructions on how and when to take the prescribed medication ${ }^{50}$ and on what to expect regarding possible side effects, and how to deal 
with them, can increase the odds of early antidepressant treatment withdrawal. ${ }^{51,52}$ Taken together, these factors can minimize the chances to persist taking medications for long enough according to clinical guidelines ${ }^{6,53,54}$ or to manage early and often transient antidepressant adverse effects. ${ }^{55}$ Moreover, prescribing multiple medications, and to a greater extent, prescribing them with complex treatment regimens increase the risk of non-adherence. Complex treatment plans, with multiple doses per day and additional requirements, which might not fit in a subject's consolidated routine, complicate treatment adherence. This is worse in subjects with aforementioned individual predisposition to poor adherence, such as adolescents or elderly subjects with cognitive impairment.

Service characteristics are key. Accessible mental health specialist treatment should ideally be available for all patients, who might need to be re-assured in the early phases of antidepressant treatment regarding potential adverse events, and who might need some clarifications or need to be reminded of specific aspects discussed in the face-to-face visit. Supporting this, frequent and regular follow-up visits increase the odds of good adherence, ${ }^{56}$ and specialist availability, including by phone, also improves antidepressant adherence. ${ }^{57}$ Thus, the lower the barriers to specialist health care, the higher and better the adherence to prescribed medications. ${ }^{58}$ In addition to health care access barriers, any medical interaction inherently depends on the therapeutic alliance between the prescriber and the patient. A good therapeutic alliance is crucial in order to maximize adherence to any prescribed medication. This is particularly the case in the management of people at the earliest stages of a disorder. ${ }^{59}$

Beyond the health care environment and the patientprescriber interaction, clinical, pharmacokinetic, and pharmacodynamic considerations should also guide antidepressant choice. Firstly, a past personal or family experience of adverse events with specific medications can reoccur with the same drug prescription, even after years. Potential adverse drug reactions or previous adverse effects of medications play an important role in the decision not to commence antidepressants and are the most important reason for treatment discontinuation. ${ }^{60}$ Similarly, family or personal history of lack of efficacy of a given medication is also a major factor leading to antidepressant discontinuation. ${ }^{61}$ Further, neglecting major pharmacokinetic or pharmacodynamic drug-drug interactions, or major dose adjustments needed for specific concomitant medical conditions, such as renal or liver dysfunction, can contribute to reducing tolerability and efficacy of antidepressants and increasing the risk of poor adherence. ${ }^{62,63}$ Finally, although most international clinical guidelines recommend classes of antidepressants for any depressive disorder, rather than specific drugs for specific clinical pictures, ${ }^{64,65}$ one-size-fits-all approaches might work worse than personalized approaches predicated on past history, adverse events, and symptom patterns.

\section{Strategies promoting antidepressant adherence}

Since both patient and prescriber play a crucial role in promoting adherence, studies on adherence and depression outcomes have shown that interventions targeting only healthcare providers generally fail, ${ }^{66,67}$ as do educational interventions targeting only patients. Consistently, previous reviews have suggested that interventions implementing combinations of strategies are more effective than single-component interventions in improving antidepressant medication adherence. ${ }^{68,69}$ For instance, collaborative care interventions, including primary care initiatives, have demonstrated significant improvements in treatment adherence during both acute and continuation phases and were associated with clinical benefit, especially in patients suffering from major depression who were prescribed adequate antidepressant dosages. ${ }^{69-71}$ Several components with heterogeneous combinations have been implemented in the available literature to promote adherence to antidepressants.

Among such a wide range of tools, some components are essential, namely routine assessment of adherence, depressive symptoms, and adverse effects, routine psychoeducation, behavioral prescriptions, affective-targeted interventions, and provider-targeted interventions. Structured, feasible, and effective interventions to promote antidepressant adherence have generally included such components. ${ }^{72-77} \mathrm{~A}$ few examples are listed in Table 1.

The first component of virtually all interventions targeting antidepressant adherence is an assessment of adherence itself. Common measures of medication adherence include patient self-report adherence assessment, electronic monitoring, pill count, and refill records. ${ }^{78}$ The variety of adherence measurement tools used reflects the absence of a "gold standard" in measuring medication adherence. ${ }^{73}$ For instance, in the Treatment Initiation and Participation Program (TIP) ${ }^{76}$ adherence was measured using the Brief Medication Questionnaire (BMQ), ${ }^{79}$ and adequate adherence was defined as taking $\geqslant 80 \%$ of the prescribed doses at 6 and 12 weeks. In another $\mathrm{RCT}^{72}$ exploring the impact of pharmacist interventions on adherence and measurable patient outcomes among depressed patients, the self-report Morisky Medication Adherence Scale (MMAS) ${ }^{80}$ was used. The MMAS, a useful screening tool for non-adherence to medications, consists of eight items addressing specific medication-taking behaviors and adherence. In a multi-center RCT, stricter criteria were set to define participants as "adherent" (Swedish Long-term Implications of Compliance Enhancing programs [SLICE] study): patients taking sertraline had to show measurable serum levels of antidepressants and/or metabolites obtained as part of therapeutic drug monitoring (TDM), self-reported assurance that she/he had taken medications as prescribed, and scheduled visits performed within the stipulated time frames. ${ }^{81}$

Two additional key components in interventions promoting adherence involve monitoring depressive symptoms and antidepressant adverse effects with validated clinical scales, since poor adherence is strongly associated with poor response and/or intolerability to medications. Regarding depressive symptoms, commonly used measures include the 24-item Hamilton Depression Rating Scale (HDRS), ${ }^{82}$ the Montgomery-Åsberg Depression Rating Scale (MADRS), ${ }^{72,81,83}$ and the Quick 
Table 1 Common strategies as part of interventions promoting medication adherence

\begin{tabular}{ll}
\hline Intervention component & Description/examples \\
\hline Assessment of adherence & $\begin{array}{l}\text { Pharmacy records or computerized administrative databases, pill counts and electronic pill containers, } \\
\text { TDM, patient self-reported assessments such as TAPQ, BMQ, and MMAS }\end{array}$ \\
Assessment of symptoms & $\begin{array}{l}\text { Clinician-rated: MADRS, HDRS } \\
\text { Patient-rated: BDI, QIDS }\end{array}$ \\
Assessment of adverse effects & $\begin{array}{l}\text { Clinician-rated: spontaneous report, TSES, UKU-SERS } \\
\text { Patient-rated: spontaneous report, FIBSER, ASEC-12, ASEX }\end{array}$ \\
$\begin{array}{l}\text { Psychoeducation with behavioral } \\
\text { prescriptions }\end{array}$ & $\begin{array}{l}\text { Psychoeducation: improve awareness of depression, clarify the role of medications for response, } \\
\text { remission and relapse prevention, and develop a relapse prevention plan } \\
\text { Behavioral prescriptions: simplified drug regimen, reminders, refill monitoring, emotional/social support } \\
\text { Psychoeducation and behavioral prescriptions delivered by different health professionals (GPs, } \\
\text { psychiatrists, nurses, psychologists, pharmacists, case managers) by different means (audiovisual } \\
\text { material or health professional direct intervention delivered by telephone, mailed material, e-mail, } \\
\text { internet, or smartphone apps) }\end{array}$
\end{tabular}

Provider-/service-targeted

Education for nurses/GPs/pharmacists/case managers

Physician reminders

Opening hours/directly accessible phone number - accessible service

Close collaboration between primary care and mental health specialists

\begin{abstract}
ASEC = Antidepressant Side-Effect Checklist; ASEX = Arizona Sexual Experience Scale; BDI = Beck Depression Inventory; BMQ = Brief Medication Questionnaire; FIBSER = Frequency, Intensity, and Burden of Side Effects Rating Scale; GP = general practitioner; HDRS = Hamilton Depression Rating Scale; MADRS = Montgomery- Asberg Depression Rating Scale; MMAS = Morisky Medication Adherence Scale; QIDS = Quick Inventory of Depressive Symptomatology-Self-Report; TAPQ = Treatment Adherence Perception Questionnaire; TDM = therapeutic drug monitoring; TSES = Toronto Side Effect Scale; UKU-SERS = UKU Side Effect Rating Scale.
\end{abstract}

Inventory of Depressive Symptomatology-Self-Report (QIDSSR). ${ }^{84}$ The Frequency, Intensity, and Burden of Side Effects Rating Scale (FIBSER) ${ }^{85}$ is used to obtain patientreported information about antidepressant adverse effects and to systematically guide antidepressant dosing and switching decisions. ${ }^{86}$

The fourth strategy to improve antidepressant adherence is psychoeducation, which generally results in behavioral prescriptions that can be delivered by a psychologist, psychiatrist, nurse practitioner, nurse, caseworker, or pharmacist via telephone or by means of print or audiovisual material. Psychoeducation includes verbal or written interventions, with a knowledge-based emphasis designed to convey information and to improve affective regulation and adherence-related behavior. Strategies implemented in the literature have been tested in individual or group settings and include the use of written, audiovisual, and mailed materials, together with telephone instructions. Behavioral prescriptions are generally intended to improve adherence by targeting, shaping, or reinforcing specific behavioral patterns. Strategies can be resource-demanding, such as supportive home visits or individual psychotherapies, but also simple, ecological, and sustainable strategies, such as targeting packaging or dosage modifications. Mail, telephone, or group interventions have been proposed as well. A notable and structured example of a well-designed psychoeducation strategy is available in the SLICE study. A starter kit was given to the patient when treatment began in the experimental Compliance Enhancement Program (CP) group, and a total of five different letters were mailed to the patient during the first 18 weeks of treatment. These letters included written educational information covering typical issues and recovery patterns associated with the successful (pharmacological) treatment of major depression. ${ }^{81,87}$ Another similar example of the psychoeducation approach consists of an information and ongoing interactive program designed by Pfizer Pharmaceuticals, called RHYTHMS, which used mailed information about depression and its pharmacological treatment. ${ }^{88,89}$

A different approach involved pharmacists in promoting adherence. Specifically, a psychoeducational program promoting antidepressant adherence, including a takehome videotape provided by pharmacists, as well as up to three coaching interventions lasting as little as 20 minutes, was effective in promoting adherence. ${ }^{90}$ Another example of psychoeducation was employed in the TIP RCT. This consisted of three 30-minute contacts scheduled during a 6 -week period just after the antidepressant was prescribed, which aimed at identifying and addressing psychological barriers to depression care, especially stigma, fears, and misconceptions of depression. Psychoeducation in the TIP study resulted in the improvement of both medication adherence and depressive symptoms. ${ }^{76,91}$

Psychoeducation content can be strictly focused on and directly target antidepressant adherence, but can also indirectly promote adherence by focusing on affective and emotion regulation. For instance, in a randomized trial of relapse prevention of depression in primary care patients, the intervention group received two primary care visits with a mental health specialist and three telephone calls over a 1-year period. This was aimed at enhancing antidepressant adherence, improving recognition of prodromal symptoms, and improving symptom monitoring, with the ultimate objective of developing a written relapse prevention plan based on antidepressant adherence. ${ }^{92}$ Telephone support has also been tested in a more intense formulation in a further RCT. Eight 
sessions of cognitive-behavioral psychotherapy delivered by telephone were administered to patients initiating antidepressant treatment in primary care settings. ${ }^{93}$ Finally, the Improving Mood-Promoting Access to Collaborative Treatment (IMPACT) was implemented in a primary care setting, involving a depression care manager supervised by a psychiatrist and a primary care expert who provided education, care management, medication support with pill-count-procedure, brief psychotherapy for depression, and problem-solving treatment in primary care. IMPACT appeared to be feasible and significantly more effective than usual care for depression among older patients regarding both antidepressant adherence and depression outcomes. ${ }^{94}$ In a cluster-randomized trial, nurses played a central role in the depression decision support team. ${ }^{95}$ Nurses were assigned to patients started on antidepressants up to 8 hours per week, and provided one early patient educational contact and depression monitoring with feedback to clinicians over 12 months. Psychoeducation focused on barriers, emphasized treatment adherence, and encouraged communication with clinicians about depression, in addition to supplemental educational materials. Moreover, patients were invited to attend a 2-hour group depression education program led by the care manager or a depression education class offered by the mental health team in one of the urban clinics. ${ }^{95}$

Preliminary and exploratory data support internet- or web-based interventions as promising approaches for reducing depressive symptoms. ${ }^{96}$ Importantly, an ongoing RCT aims to determine the effects of an evidence-based internet intervention program for older adults with depression on depressive mood symptoms, cognitive functioning, and treatment adherence in patients at risk of cardiovascular disease, i.e., in a real-world population with depression and medical comorbidities. ${ }^{97}$ The use of social media, technology (e.g., smartphones) and online materials has been identified as a key area of future practice in the promotion of mental health. ${ }^{98}$ However, there are also challenges related to data protection, privacy and security, and the "digital divide" between those who have access to the internet and those who do not, although this gap is clearly narrowing. ${ }^{99,100}$ Social media and technologybased intervention might be particularly relevant for the digitally native adolescents with depression. For instance, an RCT targeting antidepressant adherence among college students used a medication reminder app via a smartphone and revealed that the use of a medication reminder may increase adherence to antidepressants. ${ }^{101}$

For pregnant women, should antidepressant treatment be necessary, specific additional psychoeducation contents should be provided, making the patients aware of the risk for both the mother and the fetus of untreated depression itself, and discussing eventual incorrect information the patient might base her reluctancy to take antidepressants on.

The fifth component of successful antidepressant adherence intervention is targeting the healthcare system's ability to promote antidepressant adherence. Provider-targeted interventions included strategies directed towards healthcare practitioners, for instance, interventions to improve communication and provide better instructions to the patients. Healthcare can also be targeted to maximize access to care. The ultimate aim of interventions targeting healthcare providers is to warrant the former four essential components of antidepressant adherence promotion, namely, regular assessment of adherence, depressive symptoms, and adverse effects, and proper delivery of psychoeducational interventions with behavioral prescriptions. Given that, as explained above, a wide range of health professionals can deliver adherence promotion (pharmacists, nurses, nurse practitioners, general practitioners, case managers, psychologists, psychiatrists) ${ }^{70}$ healthcare institutions should support continuous educational activities and incentives in order to optimize antidepressants adherence and, ultimately, clinical depression outcomes.

In summary, a previous systematic review of 26 studies indicated that the interventions that were successful in improving both antidepressant adherence and clinical depression outcomes were primarily multifaceted interventions that employed combinations of adherence and clinical assessment, psychoeducation with behavioral prescriptions, and that implemented provider-targeted strategies. ${ }^{73}$ The efficacy of multifaceted interventions reflects the multifactorial nature of poor antidepressant adherence, which to a variable extent involves the patient, the healthcare provider, and the healthcare system. Strategies with more intensive patient monitoring and integration between mental health specialists and primary care improved the most both adherence and clinical outcomes. However, costs and personnel resources should be taken into account when implementing antidepressant adherence promotion campaigns on a large scale.

\section{Pharmacokinetic and pharmacodynamic considerations related to adherence}

The attribution of side effects to the medication is one important reason why patients discontinue antidepressants without informing clinicians. ${ }^{60}$ Overall, even if figures of adverse health outcomes due to antidepressants are inflated and seemingly driven by biased study designs, ${ }^{36}$ up to $90 \%$ of patients perceive at least one adverse event when receiving antidepressants. ${ }^{102,103}$ Most adverse events are mild (e.g., headache, sweating, dry mouth) and tolerable for patients. Other side effects can be more disturbing (e.g., nausea, diarrhea, sexual dysfunction, dizziness) and can cause treatment discontinuation. ${ }^{103,104}$ In realworld clinical practice, taking or not taking an antidepressant is frequently related to both tolerability and efficacy of the medication. Several compound-specific pharmacokinetic and pharmacodynamic properties can improve or worsen a medication's tolerability profile. In a systematic review and network meta-analysis pooling seven studies for direct comparisons and as many as 68 studies for indirect comparisons, no major efficacy or tolerability differences emerged among extended-release vs. immediaterelease antidepressants. ${ }^{105,106}$ Canadian Network for Mood and Anxiety Treatments (CANMAT) guidelines nevertheless recommend extended-release antidepressants in case of evidence of proneness to poor compliance. ${ }^{54} \mathrm{As}$ a rule, serum concentration peaks increase the risk of side 
effects. $^{63}$ Regarding pharmacodynamic characteristics, virtually every antidepressant has a unique receptor affinity. Similar to antipsychotics, ${ }^{107}$ greater affinity to a specific receptor is linked to a higher frequency of specific side effects. Whilst a detailed examination and exhaustive description of pharmacodynamic properties of each antidepressants is beyond the scope of the present focused review, Table 2 shows the difference in the frequency of some of the main side effects of the most frequently prescribed antidepressants. ${ }^{8,54}$ For instance, amitriptyline, clomipramine, and fluvoxamine have several adverse effects observed in 11 to $29 \%$ of patients, as opposed to vortioxetine, escitalopram, citalopram, and agomelatine, which seem to have the most tolerable profile.

Beyond side effect rates, which are often cited in this context as the principal cause of antidepressant discontinuation, ${ }^{108}$ few prospective studies have examined acute adverse events as a driver of discontinuation, especially in patients with severe depression. ${ }^{102}$ Different side effects may lead to treatment discontinuation in different subjects, depending on age and subjective priorities. Reasons for treatment discontinuation depend on the type of side effect and the timing of side effects after antidepressant titration, as well as side effect severity, all of which can affect patient and clinician willingness to continue antidepressant treatment. ${ }^{102}$ For instance, all antidepressants can have both short- and long-term side effects, with different effects on patients initiating acute therapy or those with established chronic depression needing longer-term maintenance treatment. ${ }^{60} \mathrm{~A}$ telephone survey conducted among 672 patients at 3 and 6 months after SSRI initiation showed that in the early phase of treatment, more patients discontinued or switched their SSRI due to an adverse effect within the first 3 months of starting $(43 \%)$, compared with the second 3 months $(27 \%)$. The adverse effect most frequently reported as the reason for early discontinuation or switching was drowsiness/fatigue (10.2\%), followed by anxiety, headache, and nausea. $^{109}$

A different picture is drawn by studies investigating longer-term discontinuation reasons. Among long-term side effects, sexual dysfunction and weight gain are two particularly burdensome side effects that may worsen with continued treatment, and possibly impact the patient's quality of life. ${ }^{60}$ Such concern is supported by a survey of 344 antidepressant-treated patients with mild to severe depression where $22 \%$ of them reported noncompliance. Among the reported side effects, "gained a lot of weight" $(27 \%)$, "unable to have an orgasm" (20\%), and "lost interest in sex" (20\%) were the most frequent adverse effects. The four adverse effects patients expressed as "extremely difficult to live with" were "weight gain" (31\%), "unable to have an erection" (25\%), "difficulty reaching orgasm" (24\%), and "tired during the day/no energy" $(21 \%) .{ }^{110}$ Moreover, according to a phone interview study that included 401 patients, 86 and 55\% reported at least one side effect and experienced one or more bothersome side effects, respectively. Again, the most common bothersome side effects were sexual dysfunction and drowsiness (17\% each). While most side effects occurred within the first 2 weeks of treatment, the majority of patients were still experiencing the same side effects at the time of interview, most notably blurred vision (85\%) and sexual dysfunction (83\%), indicating that these adverse effects may not attenuate over time. ${ }^{111}$ However, in different studies, no statistically significant association emerged between sexual dysfunction and treatment discontinuation, ${ }^{112-114}$ although decreased sexuality was commonly reported (37.2\%) and frequently described as more than mildly bothersome (22.7\%). No association emerged between other side effects and treatment discontinuation. ${ }^{109,111,115}$ Such somewhat conflicting evidence suggests that factors related to the medications' pharmacodynamic profile only partially explain risk of discontinuation, and that individual factors further determine what medication might be more tolerable. For instance, sexually active subjects are more likely to immediately drop medications interfering with sexual functioning. Subjects particularly focused on body shape and weight will not take medications inducing weight gain and subjects engaging in reading or studying activity may be less likely to tolerate medications interfering with eyesight, and subjects whose work needs high levels of vigilance may not tolerate sedating medications.

However, adverse effects can also be used therapeutically in certain cases. For instance, subjects with insomnia and weight loss might benefit from antidepressants with strong $\mathrm{H} 1$ receptor affinity, a particularly sedating agent. Importantly, beyond tolerability, if a drug is not effective and the subject affected by depressive episodes does not feel any relief/improvement/benefit, then poor adherence is as likely as for medications with several adverse events. This point is relevant because, as can be seen in Table 2, while all antidepressants outperform placebo regarding efficacy, the magnitude of the effect size ranges from an OR for response of $1.37(95 \% \mathrm{Cl} 1.16-1.63)$ for reboxetine to $2.13(95 \% \mathrm{Cl} 1.89-2.41)$ for amitriptyline. ${ }^{8}$ In this sense, amitriptyline, which is the antidepressants with the second-highest odds of being discontinued for adverse events $(\mathrm{OR}=3.11,95 \% \mathrm{Cl}$ 2.54-3.82), emerges as one of the most effective antidepressants and can be a good choice for subjects who did not show any response to other compounds. In other words, a patient might decide to accept adverse effects in exchange for the mood improvement that eventually only a TCA might exert in that specific patient.

Considering the crucial role of both tolerability and efficacy in antidepressant adherence, Figure 1 proposes a synopsis of the relationship between efficacy, expressed as the OR of response, and tolerability - namely the OR of dropout due to adverse event - and not acceptability (dropout due to any reason). ${ }^{5}$ However, no drug ranking nor frequency or association estimate can replace proper and in-depth knowledge of a patient's actual response, attitudes, and priorities, which should always be taken into account when prescribing an antidepressant.

Lastly, it is worth noting that many associations between perceived adverse events and treatment are not pharmacologically linked, and may be driven by nocebo effects. The nocebo effect is defined as nonpharmacodynamic, harmful or undesirable effects occurring after inactive treatment. Importantly, the nocebo 


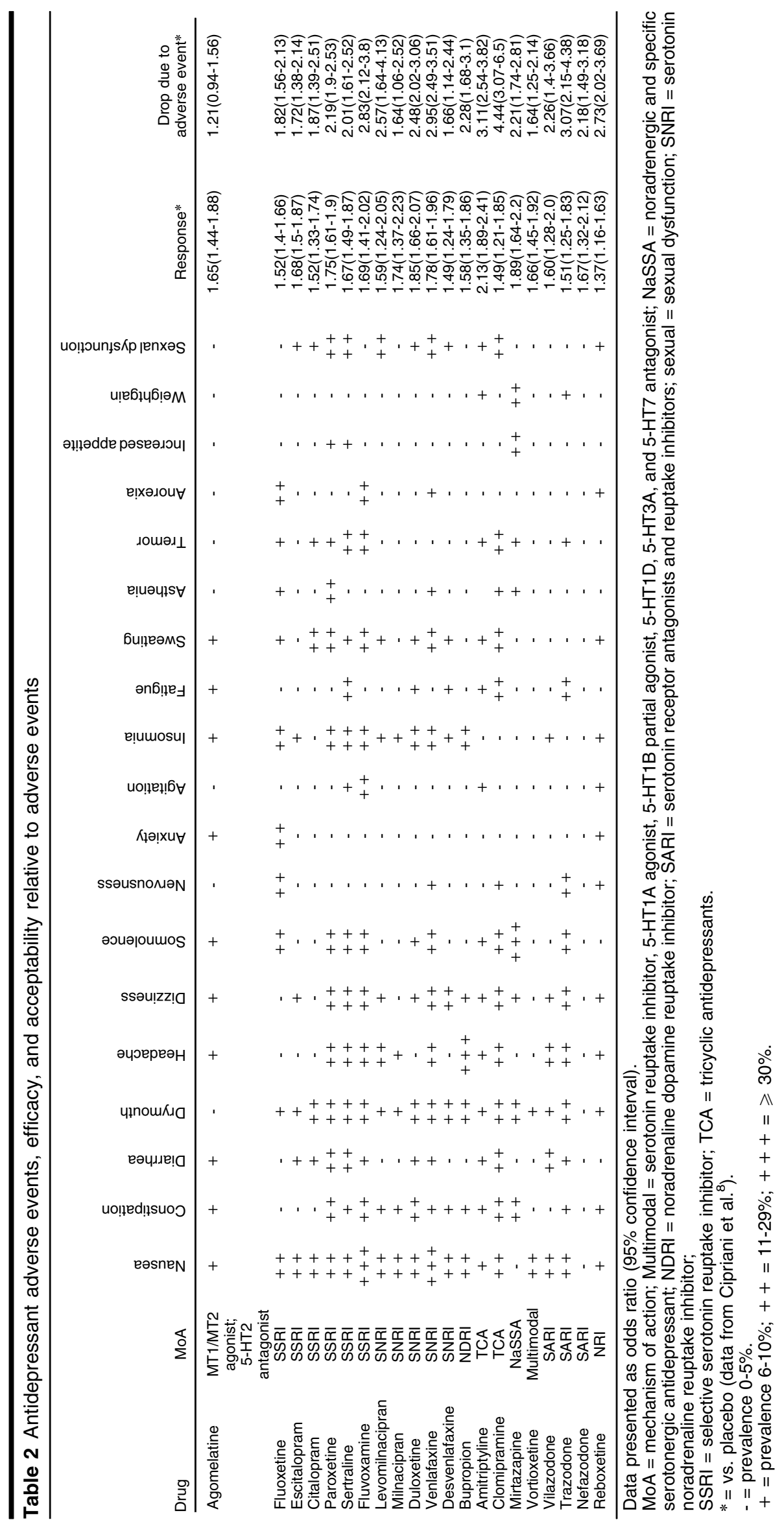


effect can be superimposed on active therapy. It is driven by classical conditioning and prior experiences leading to negative expectations concerning treatment. These include proximal factors, such as prior adverse events, and distal features, such as anxiety and trust issues. Personality elements such as type A phenotypes, core neuroticism, or pessimism increase risk of the nocebo phenomenon. Practical treatment of the nocebo effect should target knowledge and detection of the phenomenon, shaping people's expectation of treatment, the communication of potential treatment-related adverse effects, and the steps to support the treatment alliance. ${ }^{116}$ As many as $63 \%$ of adverse events in antidepressant treated people are not pharmacologically linked. ${ }^{117}$

\section{Discussion and clinical recommendations}

We considered risk factors for poor adherence, evidence supporting multidisciplinary vs. single-component interventions, ${ }^{118}$ and pharmacodynamic properties as well as the related tolerability profile of antidepressants. In response, we propose 10 recommendations to promote antidepressant adherence. Specifically, four concern the assessment phase, two concern the prescribing practice, two are related to adherence measurement, and two involve mental health services (Table 3).
Each medical interaction starts with an encounter between the health care professional and the patient, during which establishing a trust relationship and collecting medical information are key. Therefore, the first recommendation is to establish and nurture a therapeutic alliance, before prescribing any medication. Unless urgent or severe clinical features necessitate immediate treatment, medication can be started after a few visits. During these initial visits, the focus should be on listening to the patient's needs, and on understanding the patient's expectations regarding the visit and potential treatments. Too immediate, mechanical and impersonal prescription might ultimately result in rapid dropout of subjects with some fear of or stigma against medications. Similarly, if a patient has psychotic depression, guidelines for treatment of psychotic symptoms in depression should be followed, ensuring adherence to antipsychotic treatment, before any antidepressant is started. The second recommendation is to collect a thorough clinical and family history by the patient or his family members in order to exclude medications that have already proven to be ineffective or not tolerated in family members. However, maximum doses and duration of the treatment, as well as speed of titration, need to be assessed in order to evaluate if a rechallenge may be considered in the future. Moreover, detecting medical conditions, such as renal or liver dysfunction, bowel diseases, or allergies can influence

Table 3 Ten clinical recommendations to improve adherence to antidepressants

\begin{tabular}{ll}
\hline Target/domain & Actions \\
\hline $\begin{array}{l}\text { 1. Treatment alliance } \\
\text { 2. History taking }\end{array}$ & $\begin{array}{c}\text { Establish a therapeutic alliance with patients and family/significant others, if possible before } \\
\text { any pharmacological prescription. } \\
\text { Collect medical, family, and pharmacological history of efficacy and safety of antidepressants, } \\
\text { as well as medical conditions that may impact the medication choice. } \\
\text { Assess depressive symptoms at baseline and each follow-up visit with validated scales, i.e., } \\
\text { either clinician rated (e.g., MADRS, HDRS) or patient-reported (e.g., BDI, QIDS); also } \\
\text { assess adverse effects of antidepressants on these occasions (checklist, etc.) } \\
\text { Establish a plan of actions the patient has to follow in case he/she needs to talk before the next } \\
\text { appointment, i.e., enable the possibility of short needs-based telephone contacts in between } \\
\text { subsequent in-person visits. }\end{array}$
\end{tabular}

Prescription

5. Psychoeducation

6. Tailored medication choice

7. Medication regimen

Adherence

8. Adherence measurement

Service

9. Health care and medication access

10. Incentives
Offer psychoeducation to the patient and the family/caregiver, targeting awareness of the reason why medications are needed to treat depression and techniques to manage affective symptoms and their psychosocial effects.

Unless a specific antidepressant is indicated (e.g., TCA), choose the antidepressant with the best individually tailored tolerability profile in the context of a shared decision process with the patient/significant others.

Whenever possible, slow drug titration, simplified regimen, monotherapy ecologically tailored to routine preceding medication are preferable.

Assess adherence with validated scales at each follow-up visit, e.g., BMQ, or MMAS, and via TDM to assess antidepressant serum levels; propose regular TDM to promote adherence.

Remove barriers to health care access, including reduction of stigma of mental illness and treatments, minimize barriers to access to certain treatments (expertise, timely appointments, cost).

Provide incentives for monitoring and promoting adherence on the clinician side and for adhering to treatments on the patient side.

$\mathrm{BDI}=$ Beck Depression Inventory; BMQ = Brief Medication Questionnaire; HDRS = Hamilton Depression Rating Scale; MADRS = Montgomery- Asberg Depression Rating Scale; MMAS = Morisky Medication Adherence Scale; QIDS = Quick Inventory of Depressive Symptomatology; TCA = tricyclic antidepressant; TDM = therapeutic drug monitoring. 
subsequent prescription. Third, measuring depressive symptoms and assessing adverse effects is also necessary at baseline, as well as at follow-up visits, since markedly fluctuating symptoms or poor response should raise the suspicion of poor adherence that can also be related to adverse effects. Also, evidence of persistently euthymic mood in periods of good antidepressant adherence can either positively reinforce maintaining adequate medication adherence, or occasionally convey to the person the sense that they no longer need treatment. In this situation, judicious counselling is essential. In busy real-life practice, patient self-report measures for depressive symptoms and adverse events are preferable and more feasible. Fourth, clear instructions should be given to patients on how to access specialist care even beyond scheduled appointments. Barriers to quick telephone consultations in between psychiatric visits should be removed, and patients should be able to contact the mental health service for clarifications if needed. Moreover, country- and system-specific strategies to make visits and medications financially and logistically affordable are necessary. For instance, visits should ideally be scheduled as much as possible to fit the patient's working and daily routine, and medications should be selected among those covered by insurance or the national health system.

Once the assessment phase is complete, several antidepressant prescribing actions should be considered to improve adherence. According to the fifth recommendation, the patient should receive even brief psychoeducation on both the disease and the need for optimal monitoring, psychotherapeutic, and medication adherence. Psychoeducation could be delivered in a group setting, for economic and sustainability reasons, but individual settings are indicated for more intense interventions and for teaching problem-solving techniques. Sixth, regarding antidepressant choice, unless specific and valid clinical reasons indicate a specific medication, e.g., a TCA in case of a major depressive disorder resistant to other compounds, more recent antidepressants that are less frequently associated with dropout due to adverse events, such escitalopram, escitalopram, or vortioxetine should be considered as starting treatment. Generally, the antidepressant choice should be tailored to each individual patient in the context of a shared-decision process. This recommendation stems from the fact that, apart from second-line agents such as amitriptyline, the available antidepressants have roughly similar efficacy (Table 2 and Figure 1). Hence, tailored tolerability profiles should be a primary parameter to guide medication choice. Seventh, the prescribed antidepressant regimen should be simple, lean, and economically integrate into the routine and the habits a person had before starting the medication (unless unhealthy habits dominated the picture). Ideally, one medication should be started, and with a slow titration schema, in order to minimize any emerging adverse event. When several medications are prescribed, dose changes should only be made in one medication at a time in order to be able to disentangle cause and effect more effectively.

The eighth specific recommendation focuses on adherence assessment. Adherence should be routinely assessed. This includes episodes of non-adherence in the past and their potential reasons, as well as at each visit. Adherence could be measured with validated tools, such as the BMQ or MMAS. ${ }^{79,119}$ Additionally, when adherence remains unclear, or in case of poor adherence, $\mathrm{TDM}^{120,121}$ might work as an explicit tool the prescriber

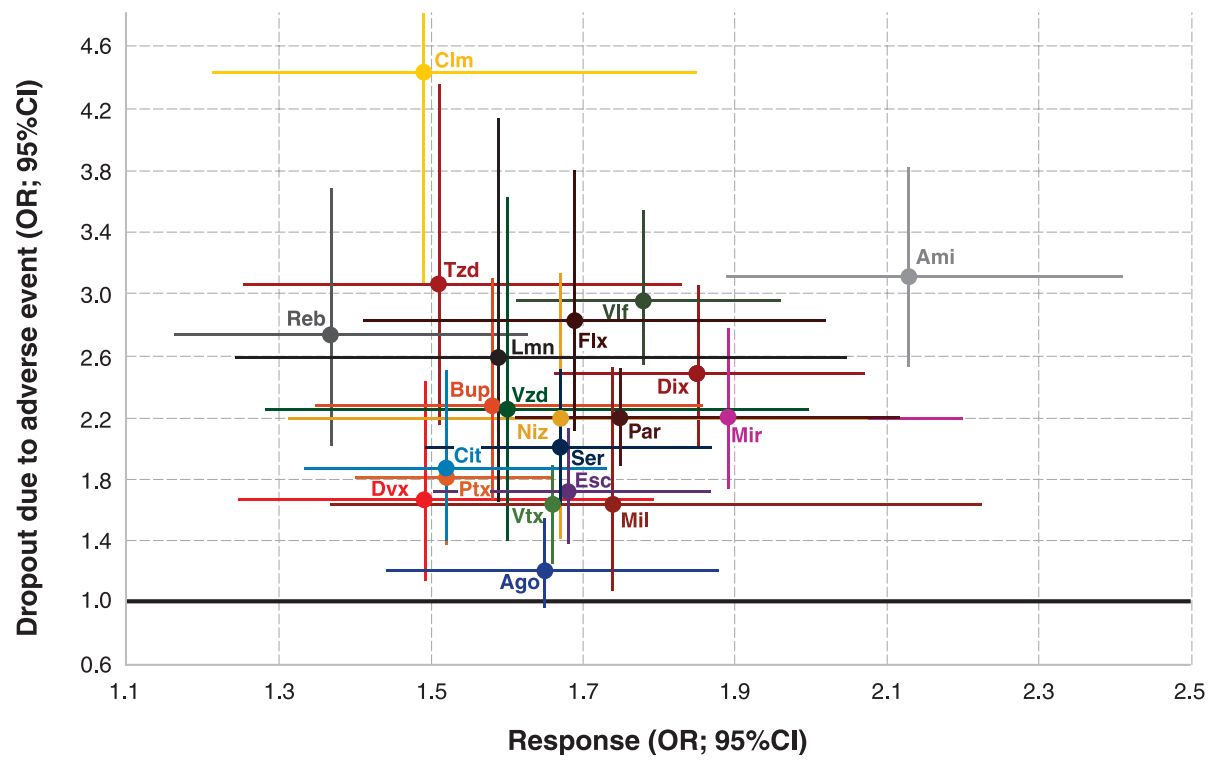

Figure 1 Efficacy and dropout due to adverse events of antidepressants. Adapted from $\mathrm{Cipriani}$ et al. ${ }^{8}$ 95\% $\mathrm{Cl}=95 \%$ confidence interval; Ago = agomelatine; Ami = amitriptyline; Bup = bupropion; Cit = citalopram; Clm = clomipramine; Dlx = duloxetine; Dvx = desvenlafaxine; Esc = escitalopram; Flx = fluoxetine; Flx = fluvoxamine; Lmn = levomilnacipran; Mil = milnacipran; Mir = mirtazapine; Nfz = nefazodone; OR = odds ratio; Par = paroxetine; Reb = reboxetine; Ser = sertraline; $\mathrm{Tzd}=$ trazodone; VIf = venlafaxine; Vtx = vortioxetine; Vzd = vilazodone. 
and the patient choose together to promote adherence. Regular utilization of TDM, if appropriately performed accordingly to recent (and unique) international guidelines, might be useful to avoid multiple drug switches in cases of pseudo-resistance to antidepressants. ${ }^{120,121}$

The final two recommendations target the mental health service to facilitate adherence promotion. Ninth, access to mental health care in general should be improved. This includes stigma reduction campaigns to improve help seeking and acceptance of psychiatric treatments and affordable care that can be accessed quickly and without complex navigation systems. Tenth, targeted strategies should be considered, including incentives for clinicians and for patients to engage in behaviors that enhance adherence. This includes incentivizing mental health services and individual professionals who show evidence of educating about, monitoring, or reinforcing adherence. For patients, incentives could include reduced health care costs when they can demonstrate adherence or adherence promoting behavior.

In summary, this focused review of the literature on antidepressant adherence in patients with depression led to the formulation of 10 clinical recommendations aimed at improving antidepressant adherence. In the future, quality indicators and/or value-based reimbursement strategies may need to incorporate adequate strategies for education, monitoring and promotion of adherence, as well as the identification and remediation of non-adherence. It is hoped that the proposed strategies, which target the prescriber, patient, and health care system, can be useful for clinicians in conceptualizing potential areas that require attention to improve antidepressant adherence and overall outcomes.

\section{Acknowledgements}

MB is supported by a National Health and Medical Research Council (NHMRC) Senior Principal Research Fellowship (1059660 and 1156072). MB has received grant/research support from the National Institutes of Health (NIH), Cooperative Research Centre, Simons Autism Foundation, Cancer Council of Victoria, Stanley Medical Research Foundation, MBF, National Health and Medical Research Council (NHMRC), Medical Research Future Fund (MRFF), Beyond Blue, Rotary Health, Avant and the Harry Windsor Foundation.

\section{Disclosure}

CUC has been a consultant and/or advisor to or has received honoraria from Alkermes, Allergan, Angelini, Bristol-Myers Squibb, Gerson Lehrman Group, IntraCellular Therapies, Janssen/J\&J, LB Pharma, Lundbeck, Medavante, Medscape, Merck, Neurocrine, Otsuka, Pfizer, ROVI, Servier, Sunovion, Takeda, and Teva; has provided expert testimony for Bristol-Myers Squibb, Janssen, and Otsuka; has served on a Data Safety Monitoring Board for Lundbeck and ROVI; has received royalties from UpToDate and grant support from Janssen and Takeda. MB has received grant/research support from the a2 Milk Company, Meat and Livestock Board, Woolworths, and Avant; has been a speaker for Astra Zeneca, Lundbeck, Merck, and Pfizer; and served as a consultant to Allergan, Astra Zeneca, Bioadvantex, Bionomics, Collaborative Medicinal Development, Lundbeck Merck, Pfizer, and Servier. The other authors have no conflicts of interest.

\section{References}

1 World Health Organization (WHO). The global burden of disease: 2004 update [Internet]. 2008; [cited 2020 Apr 28]. www.who.int/ healthinfo/global_burden_disease/2004_report_update/en/

2 Ten Have M, de Graaf R, van Dorsselaer S, Tuithof M, Kleinjan M, Penninx BW. Recurrence and chronicity of major depressive disorder and their risk indicators in a population cohort. Acta Psychiatr Scand. 2018;137:503-15.

3 Hardeveld F, Spijker J, De Graaf R, Nolen WA, Beekman AT. Prevalence and predictors of recurrence of major depressive disorder in the adult population. Acta Psychiatr Scand. 2010;122:184-91.

4 Leucht S, Hierl S, Kissling W, Dold M, Davis JM. Putting the efficacy of psychiatric and general medicine medication into perspective: review of meta-analyses. Br J Psychiatry. 2012;200:97-106.

5 Cipriani A, Furukawa TA, Salanti G, Chaimani A, Atkinson LZ, Ogawa $Y$, et al. Comparative efficacy and acceptability of 21 antidepressant drugs for the acute treatment of adults with major depressive disorder: a systematic review and network meta-analysis. Lancet. 2018;391:1357-66.

6 Bauer M, Severus E, Möller HJ, Young AH. WFSBP Task Force on Unipolar Depressive Disorders. Pharmacological treatment of unipolar depressive disorders: summary of WFSBP guidelines. Int $\mathrm{J}$ Psychiatry Clin Pract. 2017;21:166-76.

7 Carvalho AF, Sharma MS, Brunoni AR, Vieta E, Fava GA. The safety, tolerability and risks associated with the use of newer generation antidepressant drugs: a critical review of the literature. Psychother Psychosom. 2016;85:270-88.

8 Cipriani A, Zhou X, Del Giovane C, Hetrick SE, Qin B, Whittington C, et al. Comparative efficacy and tolerability of antidepressants for major depressive disorder in children and adolescents: a network meta-analysis. Lancet. 2016;388:881-90.

9 Dragioti E, Karathanos V, Gerdle B, Evangelou E. Does psychotherapy work? An umbrella review of meta-analyses of randomized controlled trials. Acta Psychiatr Scand. 2017;136:236-46.

10 Fornaro M, Anastasia A, Valchera A, Carano A, Orsolini L, Vellante $F$, et al. The FDA "black box" warning on antidepressant suicide risk in young adults: More harm than benefits?. Front Psychiatry. 2019;10:294.

11 Jamison KR. An unquite mind. New York: the New York Time Books Review; 1995.

12 Sackett DL, Haynes RB. Compliance with therapeutic regimens. Baltimore: The Johns Hopkins University; 1978.

13 Demyttenaere K. Risk factors and predictors of compliance in depression. Eur Neuropsychopharmacol. 2003;13 Suppl 3:S69-75.

14 Kripalani S, Yao X, Haynes RB. Interventions to enhance medication adherence in chronic medical conditions: a systematic review. Arch Intern Med. 2007;167:540-50.

15 Machado-Vieira R, Salvadore G, Luckenbaugh DA, Manji HK, Zarate CA Jr. Rapid onset of antidepressant action: a new paradigm in the research and treatment of major depressive disorder. J Clin Psychiatry. 2008;69:946-58.

16 Rossom RC, Shortreed S, Coleman KJ, Beck A, Waitzfelder BE, Stewart C, et al. Antidepressant adherence across diverse populations and healthcare settings. Depress Anxiety. 2016;33:765-74.

17 Lee MS, Lee HY, Kang SG, Yang J, Ahn H, Rhee M, et al. Variables influencing antidepressant medication adherence for treating outpatients with depressive disorders. J Affect Disord. 2010;123: 216-21.

18 Sheehan DV, Eaddy M, Sarnes M, Vishalpura T, Regan T. Evaluating the economic consequences of early antidepressant treatment discontinuation: a comparison between controlled-release and immediate-release paroxetine. J Clin Psychopharmacol. 2004;24: 544-8.

19 Ho SC, Chong HY, Chaiyakunapruk N, Tangiisuran B, Jacob SA. Clinical and economic impact of non-adherence to antidepressants 
in major depressive disorder: a systematic review. J Affect Disord. 2016;193:1-10.

20 De Las Cuevas C, De Leon J, Peñate W, Betancort M. Factors influencing adherence to psychopharmacological medications in psychiatric patients: a structural equation modeling approach. Patient Prefer Adherence. 2017;11:681-90.

21 De Las Cuevas C, Peñate W, Cabrera C. Perceived health control: a promising step forward in our understanding of treatment adherence in psychiatric care. J Clin Psychiatry. 2016;77:e1233-9.

22 National Institute for Health and Clinical Excellence: Guidance. Depression: The Treatment and Management of Depression in Adults (Updated Edition). Leicester: British Psychological Society; 2010.

23 Solomon DA, Keller MB, Leon AC, Mueller TI, Lavori PW, Shea MT, et al. Multiple recurrences of major depressive disorder. Am J Psychiatry. 2000;157:229-33.

24 Pompili M, Venturini P, Palermo M, Stefani H, Seretti ME, Lamis DA, et al. Mood disorders medications: Predictors of nonadherence review of the current literature. Expert Rev Neurother. 2013;13:809-25.

25 Demyttenaere K. Compliance during treatment with antidepressants. J Affect Disord. 1997;43:27-39.

26 Feetam C. Medicine taking behaviour in depression - Part 2. Prog Neurol Psychiatry. 2009;13:303.

27 DiMatteo MR, Lepper HS, Croghan TW. Depression is a risk factor for noncompliance with medical treatment: meta-analysis of the effects of anxiety and depression on patient adherence. Arch Intern Med. 2000;160:2101-7.

28 Zaninotto L, Solmi M, Veronese N, Guglielmo R, loime L, Camardese $\mathrm{G}$, et al. A meta-analysis of cognitive performance in melancholic versus non-melancholic unipolar depression. J Affect Disord. 2016;201:15-24.

29 Rivero-Santana A, Perestelo-Perez L, Pérez-Ramos J, SerranoAguilar P, De Las Cuevas C. Sociodemographic and clinical predictors of compliance with antidepressants for depressive disorders: systematic review of observational studies. Patient Prefer Adherence. 2013;7:151-69.

30 Friborg O, Martinsen EW, Martinussen M, Kaiser S, Overgård KT, Rosenvinge $\mathrm{JH}$. Comorbidity of personality disorders in mood disorders: a meta-analytic review of 122 studies from 1988 to 2010. J Affect Disord. 2014;142-154:1-11.

31 Köhling J, Ehrenthal JC, Levy KN, Schauenburg H, Dinger U. Quality and severity of depression in borderline personality disorder: a systematic review and meta-analysis. Clin Psychol Rev. 2015; 37:13-25.

32 Lai HM, Cleary M, Sitharthan T, Hunt GE. Prevalence of comorbid substance use, anxiety and mood disorders in epidemiological surveys, 1990-2014: a systematic review and meta-analysis. Drug Alcohol Depend. 2015;154:1-13.

33 Dowling NA, Cowlishaw S, Jackson AC, Merkouris SS, Francis KL, Christensen DR. Prevalence of psychiatric co-morbidity in treatment-seeking problem gamblers: a systematic review and metaanalysis. Aust N Z J Psychiatry. 2015;49:519-39.

34 Edgcomb JB, Zima B. Medication adherence among children and adolescents with severe mental illness: a systematic review and meta-analysis. J Child Adolesc Psychopharmacol. 2018;28:508-20.

35 Vega C, Becker RV, Mucha L, Lorenz BH, Eaddy MT, Ogbonnaya AO. Impact of adherence to antidepressants on healthcare outcomes and costs among patients with type 2 diabetes and comorbid major depressive disorder. Curr Med Res Opin. 2017;33:1879-89.

36 Dragioti E, Solmi M, Favaro A, Fusar-Poli P, Dazzan P, Thompson T, et al. Association of antidepressant use with adverse health outcomes: a systematic umbrella review. JAMA Psychiatry; 2019. Oct 2. doi: 10.1001/jamapsychiatry.2019.2859. [Epub ahead of print]

$37 \mathrm{Kim}$ JY, Son MJ, Son CY, Radua J, Eisenhut M, Gressier F, et al. Environmental risk factors and biomarkers for autism spectrum disorder: an umbrella review of the evidence. Lancet Psychiatry. 2019;6:590-600.

38 Hung $\mathrm{Cl}$. Factors predicting adherence to antidepressant treatment. Curr Opin Psychiatry. 2014;27:344-9.

39 Krivoy A, Balicer RD, Feldman B, Hoshen M, Zalsman G, Weizman $A$, et al. The impact of age and gender on adherence to antidepressants: a 4-year population-based cohort study. Psychopharmacology (Berl). 2015;232:3385-90.
40 Kusaslan Avci D. Evaluation of the relationship between loneliness and medication adherence in patients with diabetes mellitus: a cross-sectional study. J Int Med Res. 2018;46:3149-61.

41 Steindl C, Jonas E, Sittenthaler S, Traut-Mattausch E, Greenberg J. Understanding psychological reactance: new developments and findings. Z Psychol. 2015;223:205-14.

42 De Las Cuevas C, Peñate W, Sanz EJ. The relationship of psychological reactance, health locus of control and sense of self-efficacy with adherence to treatment in psychiatric outpatients with depression. BMC Psychiatry. 2014;14:324.

43 Kamaradova D, Latalova K, Prasko J, Kubinek R, Vrbova K, Mainerova $\mathrm{B}$, et al. Connection between self-stigma, adherence to treatment, and discontinuation of medication. Patient Prefer Adherence. 2016;10:1289-98.

44 Ayalon L, Areán PA, Alvidrez J. Adherence to antidepressant medications in black and Latino elderly patients. Am $\mathrm{J}$ Geriatr Psychiatry. 2005;13:572-80.

45 Mårdby AC, Schiöler L, Sundell KA, Bjerkeli $P$, Lesén $E$, Jönsson AK. Adherence to antidepressants among women and men described with trajectory models: a Swedish longitudinal study. Eur J Clin Pharmacol. 2016;72:1381-9.

46 Bosworth HB, Voils CI, Potter GG, Steffens DC. The effects of antidepressant medication adherence as well as psychosocial and clinical factors on depression outcomeamong older adults. Int $\mathrm{J}$ Geriatr Psychiatry. 2008;23:129-34.

47 Delgado PL. Approaches to the enhancement of patient adherence to antidepressant medication treatment. J Clin Psychiatry. 2000;61 Suppl 2:6-9.

48 Tursi MF, Baes CV, Camacho FR, Tofoli SM, Juruena MF. Effectiveness of psychoeducation for depression: a systematic review. Aust N Z J Psychiatry. 2013;47:1019-31.

49 Weck F, Weigel M, Hautzinger M, Barocka A, Schlösser RG, Stangier $U$. Relapses in recurrent depression 1 year after psychoeducational treatment: the role of therapist adherence and competence, and the therapeutic alliance. Psychiatry Res. 2012;195:51-5.

50 Demyttenaere K, Enzlin P, Dewé W, Boulanger B, De Bie J, De Troyer W, et al. Compliance with antidepressants in a primary care setting, 1: beyond lack of efficacy and adverse events. J Clin Psychiatry. 2001;62 Suppl 22:30-3.

51 Demyttenaere K. Compliance and acceptance in antidepressant treatment. Int J Psychiatry Clin Pract. 2001;2001:29-35.

52 David DJ, Gourion D. [Antidepressant and tolerance: determinants and management of major side effects]. Encephale. 2016;42:553-61.

53 Bauer M, Severus E, Köhler S, Whybrow PC, Angst J, Möller HJ, et al. World Federation of Societies of Biological Psychiatry (WFSBP) guidelines for biological treatment of unipolar depressive disorders. part 2: maintenance treatment of major depressive disorder-update 2015. World J Biol Psychiatry. 2015;16:76-95.

54 Kennedy SH, Lam RW, McIntyre RS, Tourjman SV, Bhat V, Blier P, et al. Canadian Network for Mood and Anxiety Treatments (CANMAT) 2016 clinical guidelines for the management of adults with major depressive disorder: Section 3. Pharmacological Treatments. Can J Psychiatry. 2016;61:540-60.

55 Fornaro M, Anastasia A, Novello S, Fusco A, Pariano R, De Berardis D, et al. The emergence of loss of efficacy during antidepressant drug treatment for major depressive disorder: an integrative review of evidence, mechanisms, and clinical implications. Pharmacol Res. 2019;139:494-502.

56 Benner JS, Tierce JC, Ballantyne CM, Prasad C, Bullano MF, Willey VJ, et al. Follow-up lipid tests and physician visits are associated with improved adherence to statin therapy. Pharmacoeconomics. 2004;22 Suppl 3:13-23.

57 Cameron C, Habert J, Anand L, Furtado M. Optimizing the management of depression: primary care experience. Psychiatry Res. 2014;220 Suppl 1:S45-57.

58 Firth J, Siddiqi N, Koyanagi A, Siskind D, Rosenbaum S, Galletly C, et al. The Lancet Psychiatry Commission: a blueprint for protecting physical health in people with mental illness. Lancet Psychiatry. 2019;6:675-712.

59 Macneil CA, Hasty MK, Berk M, Henry L, Evans M, Redlich C, et al. Psychological needs of adolescents in the early phase of bipolar disorder: implications for early intervention. Early Interv Psychiatry. 2011;5:100-7. 
60 Clayton $\mathrm{AH}$, Favit A. Concerns in depression treatment: sexual dysfunction and weight gain [Internet]. 2007 Jun 1 [cited 2010 Apr 28]. primarypsychiatry.com/concerns-in-depression-treatment-sexual-dys function-and-weight-gain/

61 Fortney JC, Pyne JM, Edlund MJ, Stecker T, Mittal D, Robinson DE, et al. Reasons for antidepressant nonadherence among veterans treated in primary care clinics. J Clin Psychiatry. 2011;72:827-34.

62 Gillman PK. Tricyclic antidepressant pharmacology and therapeutic drug interactions updated. Br J Pharmacol. 2007;151:737-48.

63 Mandrioli R, Protti M, Mercolini L. New-Generation, Non-SSRI antidepressants: therapeutic drug monitoring and pharmacological interactions. Part 1: SNRIs, SMSs, SARIs. Curr Med Chem. 2018; 25:772-92.

64 Lam RW, Mclntosh D, Wang J, Enns MW, Kolivakis T, Michalak EE, et al. Canadian network for mood and anxiety treatments (CANMAT) 2016 clinical guidelines for the management of adults with major depressive disorder: Section 1. Disease burden and principles of care. Can J Psychiatry. 2016;61:510-23.

65 National Institute for Health and Care Excellence (NICE). The NICE guideline on the treatment and management of depression in adults: updated edition. 2010 [cited 2020 Apr 28]. www.nice.org.uk/gui dance/cg90/evidence/full-guideline-pdf-4840934509.

66 Lin EHB, Katon WJ, Simon GE, Von Korff M, Bush TM, Rutter CM, et al. Achieving guidelines for the treatment of depression in primary care: is physician education enough? Med Care. 1997;35: 831-42.

67 Thompson C, Kinmonth AL, Stevens L, Peveler RC, Stevens A, Ostler KJ, et al. Effects of a clinical-practice guideline and practicebased education on detection and outcome of depression in primary care: Hampshire Depression Project randomised controlled trial. Lancet. 2000;355:185-91.

68 Pampallona S, Bollini P, Tibaldi G, Kupelnick B, Munizza C. Patient adherence in the treatment of depression. $\mathrm{Br} \mathrm{J}$ Psychiatry. 2002; 180:104-9.

69 Vergouwen AC, Bakker A, Katon WJ, Verheij TJ, Koerselman F. Improving adherence to antidepressants: a systematic review of interventions. J Clin Psychiatry. 2003;64:1415-20.

70 Katon W, Von Korff M, Lin E, Simon G, Walker E, Unützer J, et al. Stepped collaborative care for primary care patients with persistent symptoms of depression: a randomized trial. Arch Gen Psychiatry. 1999;56:1109-15.

71 Thota AB, Sipe TA, Byard GJ, Zometa CS, Hahn RA, McKnight-Eily $\mathrm{LR}$, et al. Collaborative care to improve the management of depressive disorders: A community guide systematic review and meta-analysis. Am J Prev Med. 2012;42:525-38.

72 Aljumah K, Hassali MA. Impact of pharmacist intervention on adherence and measurable patient outcomes among depressed patients: a randomised controlled study. BMC Psychiatry. 2015; 15:219.

73 Chong WW, Aslani P, Chen TF. Effectiveness of interventions to improve antidepressant medication adherence: a systematic review. Int J Clin Pract. 2011;65:954-75.

74 Hinton L, Zweifach M, Oishi S, Tang L, Unützer J. Gender disparities in the treatment of late-life depression: qualitative and quantitative findings from the IMPACT trial. Am J Geriatr Psychiatry. 2006; 14:884-92.

75 Pino-Sedeño T Del, Peñate W, de Las Cuevas C, Valcarcel-Nazco C, Fumero A, Serrano-Pérez PG, et al. Effectiveness and costeffectiveness of a multicomponent intervention to improve medication adherence in people with depressive disorders - mapdep: a study protocol for a cluster randomized controlled trial. Patient Prefer Adherence. 2019;13:303-19.

76 Sirey JA, Banerjee S, Marino P, Bruce ML, Halkett A, Turnwald M, et al. Adherence to depression treatment in primary care a randomized clinical trial. JAMA Psychiatry. 2017;74:1129-35.

77 Williams JW Jr, Gerrity M, Holsinger T, Dobscha S, Gaynes B, Dietrich A. Systematic review of multifaceted interventions to improve depression care. Gen Hosp Psychiatry. 2007;29:91-116.

78 Kane JM, Kishimoto T, Correll CU. Non-adherence to medication in patients with psychotic disorders: epidemiology, contributing factors and management strategies. World Psychiatry. 2013;12:216-26.

79 Svarstad BL, Chewning BA, Sleath BL, Claesson C. The brief medication questionnaire: a tool for screening patient adherence and barriers to adherence. Patient Educ Couns. 1999;37:113-24.
80 Uchmanowicz B, Jankowska EA, Uchmanowicz I, Morisky DE. Selfreported medication adherence measured with morisky medication adherence scales and its determinants in hypertensive patients aged $\geqslant 60$ years: a systematic review and meta-analysis. Front Pharmacol. 2019;10:168.

81 Åkerblad AC, Bengtsson F, Von Knorring L, Ekselius L. Response, remission and relapse in relation to adherence in primary care treatment of depression: a 2-year outcome study. Int Clin Psychopharmacol. 2006;21:117-24.

82 Hamilton M. A rating scale for depression. J Neurol Neurosurg Psychiatry. 1960;23:56-62.

83 Montgomery SA, Asberg M. A new depression scale designed to be sensitive to change. Br J Psychiatry. 1979;134:382-9.

84 Rush AJ, Trivedi MH, Ibrahim HM, Carmody TJ, Arnow B, Klein DN, et al. The 16-item quick inventory of depressive symptomatology (QIDS), clinician rating (QIDS-C), and self-report (QIDS-SR): a psychometric evaluation in patients with chronic major depression. Biol Psychiatry. 2003;54:573-83.

85 Wisniewski SR, Rush AJ, Balasubramani GK, Trivedi MH, Nierenberg AA; STARD Investigators. Self-rated global measure of the frequency, intensity, and burden of side effects. J Psychiatr Pract. 2006;12:71-9.

86 Guo T, Xiang YT, Xiao L, Hu CQ, Chiu HF, Ungvari GS, et al. Measurement-based care versus standard care for major depression: a randomized controlled trial with blind raters. Am J Psychiatry. 2015;172:1004-13.

87 Åkerblad AC, Bengtsson F, Holgersson M, von Knorring L, Ekselius $\mathrm{L}$. Identification of primary care patients at risk of nonadherence to antidepressant treatment. Patient Prefer Adherence. 2008;2:379-86.

88 Kutcher S, Leblanc J, Maclaren C, Hadrava V. A randomized trial of a specific adherence enhancement program in sertraline-treated adults with major depressive disorder in a primary care setting. Prog Neuro Psychopharmacology Biol Psychiatry. 2002;26:591-6.

89 Mundt JC, Clarke GN, Burroughs D, Brenneman DO, Griest JH. Effectiveness of antidepressant pharmacotherapy: the impact of medication compliance and patient education. Depress Anxiety. 2001;13:1-10.

90 Brook $\mathrm{OH}$, Van Hout $\mathrm{H}$, Stalman W, Nieuwenhuyse $\mathrm{H}$, Bakker B, Heerdink $E$, et al. A pharmacy-based coaching program to improve adherence to antidepressant treatment among primary care patients. Psychiatr Serv. 2005;56:487-9.

91 Sirey JA, Bruce ML, Kales HC. Improving antidepressant adherence and depression outcomes in primary care: the treatment initiation and participation (TIP) program. Am J Geriatr Psychiatry. 2010;18:554-62.

92 Katon W, Rutter C, Ludman EJ, Von Korff M, Lin E, Simon G, et al. A randomized trial of relapse prevention of depression in primary care. Arch Gen Psychiatry. 2001;58:241-7.

93 Simon GE, Ludman EJ, Tutty S, Operskalski B, Von Korff M. Telephone psychotherapy and telephone care management for primary care patients starting antidepressant treatment: a randomized controlled trial. JAMA. 2004;292:935-42.

94 Unützer J, Katon W, Callahan CM, Williams JW Jr, Hunkeler E, Harpole L, et al. Collaborative care management of late-life depression in the primary care setting: a randomized controlled trial. JAMA. 2002;288:2836-45.

95 Dobscha SK, Corson K, Hickam DH, Perrin NA, Kraemer DF, Gerrity MS. Depression decision support in primary care: a cluster randomized trial. Ann Intern Med. 2006;145:477-87.

96 Xiang X, Wu S, Zuverink A, Tomasino KN, An R, Himle JA. Internetdelivered cognitive behavioral therapies for late-life depressive symptoms: a systematic review and meta-analysis. Aging Ment Heal. 2019 Mar. 27:1-11. doi: 10.1080/13607863.2019.1590309. [Epub ahead of print]

97 Cockayne NL, Glozier N, Naismith SL, Christensen H, Neal B, Hickie IB. Internet-based treatment for older adults with depression and co-morbid cardiovascular disease: protocol for a randomised, double-blind, placebo controlled trial. BMC Psychiatry. 2011;11:10.

98 Firth J, Torous J, Nicholas J, Carney R, Pratap A, Rosenbaum S, et al. The efficacy of smartphone-based mental health interventions for depressive symptoms: a meta-analysis of randomized controlled trials. World Psychiatry. 2017;16:287-98.

99 Hollis C, Morriss R, Martin J, Amani S, Cotton R, Denis M, et al. Technological innovations in mental healthcare: harnessing the digital revolution. Br J Psychiatry. 2015;206:263-5. 
100 Bevan Jones R, Thapar A, Stone Z, Thapar A, Jones I, Smith D, et al. Psychoeducational interventions in adolescent depression: a systematic review. Patient Educ Couns. 2018;101:804-16.

101 Hammonds T, Rickert K, Goldstein C, Gathright E, Gilmore S, Derflinger B, et al. Adherence to antidepressant medications: a randomized controlled trial of medication reminding in college students. J Am Coll Heal. 2015;63:204-8.

102 Goethe JW, Woolley SB, Cardoni AA, Woznicki BA, Piez DA Selective serotonin reuptake inhibitor discontinuation: side effects and other factors that influence medication adherence. J Clin Psychopharmacol. 2007;27:451-8.

103 Gartlehner G, Hansen RA, Kahwati L, Lohr KN, Gaynes B, Carey T. Drug class review on second generation antidepressants [Internet]. 2005 Jul [cited 2010 Apr 28]. www.ohsu.edu/sites/default/ files/2019-01/AD2_final_-report-and-evidence-tables_update-1_JUL_ 05.pdf

104 Hansen RA, Gartlehner G, Lohr KN, Gaynes BN, Carey TS. Efficacy and safety of second-generation antidepressants in the treatment of major depressive disorder. Ann Intern Med. 2005;143:415-26.

105 Bauer M, Severus E, Möller HJ, Young AH. WFSBP Task Force on Unipolar Depressive Disorders. Pharmacological treatment of unipolar depressive disorders: summary of WFSBP guidelines. Int $\mathrm{J}$ Psychiatry Clin Pract. 2017;21:166-76.

106 Nussbaumer B, Morgan LC, Reichenpfader U, Greenblatt A, Hansen RA, Van Noord M, et al. Comparative efficacy and risk of harms of immediate- versus extended-release second-generation antidepressants: a systematic review with network meta-analysis. CNS Drugs. 2014;28:699-712.

107 Solmi M, Murru A, Pacchiarotti I, Undurraga J, Veronese N, Fornaro $M$, et al. Safety, tolerability, and risks associated with first-and second-generation antipsychotics: a state-of-the-art clinical review. Ther Clin Risk Manag. 2017;13:757-77.

108 Mitchell AJ. High medication discontinuation rates in psychiatry: how often is it understandable? J Clin Psychopharmacol. 2006;26: 109-12.

109 Bull SA, Hunkeler EM, Lee JY, Rowland CR, Williamson TE, Schwab JR, et al. Discontinuing or switching selective serotoninreuptake inhibitors. Ann Pharmacother. 2002;36:578-84.

110 Ashton AK, Jamerson BD, Weinstein WL, Wagoner C. Antidepressant-related adverse effects impacting treatment compliance: results of a patient survey. Curr Ther Res Clin Exp. 2005;66:96-106.
$111 \mathrm{Hu}$ XH, Bull SA, Hunkeler EM, Ming E, Lee JY, Fireman B, et al. Incidence and duration of side effects and those rated as bothersome with selective serotonin reuptake inhibitor treatment for depression: Patient report versus physician estimate. J Clin Psychiatry. 2004;65:959-65

112 Gartlehner G, Hansen RA, Carey TS, Lohr KN, Gaynes BN, Randolph LC. Discontinuation rates for selective serotonin reuptake inhibitors and other second-generation antidepressants in outpatients with major depressive disorder: a systematic review and meta-analysis. Int Clin Psychopharmacol. 2005;20:59-69.

113 Gumnick JF, Nemeroff CB. Problems with currently available antidepressants. J Clin Psychiatry. 2000;61 Suppl 10:5-15.

114 Bolling MY, Kohlenberg RJ. Reasons for quitting serotonin reuptake inhibitor therapy: paradoxical psychological side effects and patient satisfaction. Psychother Psychosom. 2004;73:380-5.

115 Bull SA, Hu XH, Hunkeler EM, Lee JY, Ming EE, Markson LE, et al. Discontinuation of use and switching of antidepressants: influence of patient-physician communication. JAMA. 2002;288:1403-9.

116 Data-Franco J, Berk M. The nocebo effect: a clinicians guide. Aust N Z J Psychiatry. 2013;47:617-23.

117 Dodd S, Schacht A, Kelin K, Dueñas H, Reed VA, Williams LJ, et al. Nocebo effects in the treatment of major depression: results from an individual study participant-level meta-analysis of the placebo arm of duloxetine clinical trials. J Clin Psychiatry. 2015;76:702-11.

118 Bambauer KZ, Adams AS, Zhang F, Minkoff N, Grande A, Weisblatt $\mathrm{R}$, et al. Physician alerts to increase antidepressant adherence: fax or fiction? Arch Intern Med. 2006;166:498-504.

119 De Las Cuevas C, Peñate W. Psychometric properties of the eightitem Morisky Medication Adherence Scale (MMAS-8) in a psychiatric outpatient setting. Int J Clin Heal Psychol. 2015;15:121-9.

120 Hiemke C, Bergemann N, Clement HW, Conca A, Deckert J, Domschke $\mathrm{K}$, et al. Consensus guidelines for therapeutic drug monitoring in neuropsychopharmacology: update 2017. Pharmacopsychiatry. 2018;51:9-62.

121 Schoretsanitis G, Kane JM, Correll CU, Marder SR, Citrome L, Newcomer JW, et al. Blood levels to optimize antipsychotic treatment in clinical practice; a joint consensus statement of the American Society of Clinical Psychopharmacology (ASCP) and the Therapeutic Drug Monitoring (TDM) Task Force of the Arbeitsgemeinschaft für Neuropsychopharmakologie und Pharmakopsychiatrie (AGNP). J Clin Psychiatry. Forthcoming 2020. 